\title{
Synthesis of silver nanocomposite hydrogels based on Poly (acrylic acid) and Poly (vinyl pyrrolidone) grafted onto Salep biopolymer and its use in drug release
}

Research Article

\section{Ghasem Rezanejade Bardajee $^{1 *}$, Hanieh Mostashfi ${ }^{1}$, Zari Hooshyar ${ }^{1}$}

\author{
1. Department of Chemistry, Payame Noor University, Tehran, Iran.
}

\begin{abstract}
This study aimed to synthesize a silver nanocomposite hydrogel based on poly (acrylic acid) and poly (vinyl pyrrolidone) grafted onto salep biopolymer and its use in controlled drug release. Drug release is one of the medicine goals that have been happening in the different methods, such as injections, pills or sprays. The useful drug dose, has measured by the drug concentration in the blood system, in the specific time. Researches have shown, in above methods, at the first time there is a high concentration of drug in the blood and by passing the time, this concentration decreases, so for achieve the useful drug dose, more drug is needed which it usually causes the increasing of the drug side effects. Thus for preventing these side effects, controlled drug release is investigated in this research. To identify the synthesized hydrogel, Fourier transform infrared spectroscopy (FTIR, scanning electron microscopy (SEM), transmission electron microscopy (TEM), and thermometric gravimetric analysis (TGA) were used. The results showed that the release of deferasirox from the silver nanocomposite hydrogel network is related to the $\mathrm{pH}$ of the environment. In addition, the biodegradability and biocompatibility of this system have led to its use in the pharmaceutical industry.
\end{abstract}

Key Words: Silver nanocomposite, Hydrogel, Salep biopolymer, Drug release.

\section{Introduction}

Research has shown that in different methods of drug delivery, first a high concentration of the drug enters the bloodstream and decreases over time. Therefore, to receive an effective dose of the drug, more of it should be consumed, which increases the side effects of the drug (1]. To solve this problem, many efforts have been made in recent years to expand the use of nanotechnology in drug formulation. Besides, since drug delivery efficiency is directly dependent on the size of nanoparticles, nanoparticle formulation can increase the access of the biological system to the drug and improve its controlled and consistent release, and reduce its side effects.

Nanotechnology is a set of processes for the separation, integration, and formation of materials the size of an atom or a molecule (2]. Reducing the size and reaching the nanoscale changes many physical (boiling point, melting point, magnetic properties, etc.) and chemical properties (catalytic activity, light absorption, electrical and thermal conductivity, etc.). Some applications of nanotechnology include drug delivery,

* Corresponding Author:

Ghasem Rezanejade Bardajee

Department of Chemistry,

Payame Noor University,

PO BOX 19395-3697,

Tehran, Iran.

Email Id: rezanejad@pnu.ac.ir water purification, nanotransistors, and solar cells (3]. Since many of the physical and chemical interactions of materials are controlled by their surface, nanostructures can exhibit completely different properties for larger materials with the same composition (4].

In the last decade of the twentieth century, a new field called nanocomposites was introduced in the field of composite science and technology. A nanocomposite is a composite that has at least one of its components is less than 100 nanometers (5].

Nanocomposites are composed of two phases: The first phase which is the base or matrix of the nanocomposite is a crystal structure made of polymer, metal, or ceramic, and the second phase is composed of nanometer-scale particles that act as reinforcing particles or fillers and are distributed in the first phase for specific purposes such as strength, resistance, electrical conductivity or magnetic properties (6].

The present study aimed to introduce a new, easy and eco-friendly method for the synthesis of silver nanocomposite hydrogels based on poly (acrylic acid) and poly (vinylpyrrolidone) grafted onto salep biopolymer, and investigate its effect on controlled drug release.

Hydrogels are three-dimensional lattice polymers that can absorb and retain water and aqueous solutions even under pressure due to their hydrophilic functional groups in their structure. Crosslinking results in latticed hydrogels, causing these polymers to absorb water and swell in aqueous media but are not dissolved (7]. Of all synthetic biomaterials, hydrogels are most 
Ghasem Rezanejade Bardajee et.al., Synthesis of silver nanocomposite hydrogels grafted onto Salep biopolymer

similar to natural living tissues due to their high water content in their swollen but strong structure.

Synthesizing the gel system with silver nanoparticles $\left(\mathrm{AgNO}_{3}\right)$ is a suitable method for applications such as controlled drug release and wound healing. The presence of biopolymers in the environment of aqueous solutions contributes to the process of nucleation and growth of nanoparticles.

Among the various enhancers used in polymers, silver nanoparticles are of particular importance due to their unique electrical (8], optical (9], catalytic (10], and especially antibacterial properties. To take full advantage of these properties, silver nanocomposites must be well dispersed on the surface of the host polymer. Otherwise, their antimicrobial properties are greatly reduced. Therefore, the smaller the nanoparticle size, the possibility of dispersion increases at the base polymer surface (11].

To synthesize nanocomposites, make them dispersed on the surface of the host polymer, and thus benefit from the properties of silver nanoparticles, salep biopolymer was used in this study. Deferasirox was also used to evaluate the controlled drug release, to maximize its effectiveness, and reduce its side effects.

\section{Methodology}

In this study, silver nanocomposite hydrogels were synthesized hydrothermally and their swelling behavior in different environments was investigated. Besides, silver nanocomposite hydrogels were optimized using the classical method. The experiments performed in this study included measuring the absorption rate in aqueous and organic solutions, measuring the absorption rate at different concentrations of potassium chloride salts and polyvalent salts, measuring the absorption under pressure, and how to load and release the drug.

\section{Raw materials}

Salep polysaccharide was prepared from a plant. Methylenebisacrylamide (MBA), ammonium persulfate (APS), vinyl pyrrolidone (VP), and acrylic acid (AA) were purchased from Merck, Germany. Hydrochloric acid was purchased from Royalex Company, India, and ethanol was provided from domestic products in Iran. Silver nitrate $\left(\mathrm{AgNO}_{3}\right)$ was purchased from Fluka and used without purification. To prepare the silver nanocomposite hydrogel and measure its water absorption, double distilled water (DDW) was used.

\section{Instrumental analysis}

The infrared spectra of the samples were measured by Jasco 4200 FT-IR on the bed of potassium bromide tablets. Shimadzu UV-visible 1650 PC was used to capture UV spectra.

To analyze the morphology of the surfaces of the synthesized silver nanocomposite hydrogels, scanning electron microscopy (SEM; Philips model, XL30) images were used. Particle size was measured using Zeiss TEM images. Thermogravimetric analysis (TGA) under nitrogen atmosphere was performed by
Pyris Dimmand TG / DTA. The temperature efficiency of the device was 25 to $750{ }^{\circ} \mathrm{C}$ per minute. A pH meter (AZ Company) was used to investigate the behavior of the samples at different $\mathrm{pH}$ values. A mechanical stirrer (Control, Heidolph RZR, 2102) was used for mechanical agitation in different stages of silver nanocomposite hydrogel synthesis.

\section{Measuring the water absorption rate}

The tea-bag method was used to measure the water absorption rate of silver nanocomposite hydrogel over time. To this end, $0.02 \mathrm{~g}$ of synthesized hydrogel powder was poured into a cloth bag similar to a tea-bag and immersed in $200 \mathrm{ml}$ of double distilled water. When the hydrogel was swollen, the bag was hanged to remove excess water and the swelling capacity was measured using Eq. (1).

Where $\mathrm{W}_{0}$ indicates the weight of the empty tea-bag and $\mathrm{W}_{1}$ is the weight of the swollen hydrogel in the bag:

$$
\text { Swelling }(\mathrm{g} / \mathrm{g})=\left(\mathrm{W}_{1}-\mathrm{W}_{0}\right) / \mathrm{W}_{0}
$$

\section{Synthesis of silver nanocomposite hydrogels}

APS was used as a primer for the synthesis of silver nanocomposite hydrogels and MBA was used as a crosslinking agent. AA and VP were used as monomers and salep as a substrate for the synthesis of silver nanoparticles.

\section{Optimization of silver nanocomposite hydrogels}

Silver nanocomposite hydrogels were synthesized to increase water absorption capacity. This phase of the experiment was performed to optimize $\mathrm{AgNO}_{3}, \mathrm{MBA}, \mathrm{APS}, \mathrm{AA}$, and VP values. In all stages of the experiment, the amount of hydrogel powder passed through the sieve was $0.02 \mathrm{~g}$, and the water absorption rate after five hours.

Environmental and laboratory effects on the swelling rate of synthesized silver nanocomposite hydrogels

\section{Investigating the time effect}

To assess the effect of time on the absorption rate of silver nanocomposite hydrogels, $0.02 \mathrm{~g}$ of hydrogel powder was poured into a mesh and immersed in $200 \mathrm{ml}$ of double distilled water (using the tea-bag method) in this study water absorption rates were measured every half an hour during the five hours test.

\section{The effect of temperature}

To assess the effect of temperature on the hydrogel water absorption rate, $0.02 \mathrm{~g}$ of hydrogel was immersed in a beaker containing $200 \mathrm{ml}$ of doubledistilled water and placed in a water bath at the desired temperature. The water absorption rate at each temperature was reported after five hours.

\section{The effect of pressure}

To measure the water absorption rate of silver nanocomposite hydrogels under pressure, $0.02 \mathrm{~g}$ of the synthesized hydrogel powder was poured evenly on the filter mesh, and a weight of a certain mass with the 
Teflon cylinder was placed on the hydrogel particles so that the Teflon cylinder can move easily in the glass cylinder. Below the mesh was a porous ceramic plate inside a petri dish containing water, and over time, the kinetics of water absorption under pressure (AUL), which exerted a pressure of 0.03 psi on the hydrogel, was measured.

\section{The effect of ethanol and water}

At this stage, to compare the rates of absorption of water and organic solvents, a mixture of ethanol and water with $20,40,60,80$, and $100 \%$ was used and the results were reported after five hours.

\section{The effect of $\mathrm{KCl}$ salt with different concentrations}

This experiment was performed to evaluate the absorption rate of $\mathrm{KCl}$ saline solution with concentrations of $0.001,0.01,0.1$, and $0.5 \mathrm{M}$, and the absorption rates were reported after five hours.

\section{The effect of monovalent, divalent, and trivalent salts}

Potassium chloride $(\mathrm{KCl})$ and sodium chloride $(\mathrm{NaCl})$ were used to measure the rate of the hydrogel in absorbing the monovalent salt solutions. Barium chloride $\left(\mathrm{BaCl}_{2}\right)$ and calcium chloride $\left(\mathrm{CaCl}_{2}\right)$ were used to measure the absorption rates of divalent salt solutions. Besides, aluminum chloride $\left(\mathrm{AlCl}_{3}\right)$ was also used to measure the absorption rate of the trivalent salt solution. To compare the absorption rate of the above solutions, $0.1 \mathrm{M}$ solution was prepared from each of the salts and the results were reported after five hours.

\section{Intelligent behavior of silver nanocomposite hydrogels (pH effect)}

At this stage, $\mathrm{HCl}$ and $\mathrm{NaOH}$ were used to prepare solutions with $\mathrm{pH}=2, \mathrm{pH}=4, \mathrm{pH}=6, \mathrm{pH}=7$, $\mathrm{pH}=8$, and $\mathrm{pH}=10$. Then, the water absorption rates of silver nanocomposite hydrogel in the above solutions were measured after five hours.

\section{Drug release \\ Deferasirox loading}

To load the drug on the silver nanocomposite hydrogel, a beaker containing $5 \mathrm{ml}$ of $0.0019 \mathrm{M}$ of deferasirox was placed in a water bath at $40^{\circ} \mathrm{C}$ for 5 minutes. Then $0.05 \mathrm{~g}$ of the synthesized hydrogel powder was added to the drug solution and the contents of the beaker were homogenized by the magnet. After complete absorption of the drug solution by the hydrogel powder, the swollen hydrogel was dried in an oven at $50{ }^{\circ} \mathrm{C}$. The dried hydrogel was then rinsed with pure ethanol and passed through a sieve, and the UV spectra of ethanol were measured under the sieve. In the last step, the hydrogel was dried again in the oven at 50 ${ }^{\circ} \mathrm{C}$ and the drug was prepared for release.

\section{Drug release}

At this stage, $20 \mathrm{ml}$ of a buffer solution with $\mathrm{pH}$ $=2$ and $\mathrm{pH}=8$, equivalent to the acidity of the stomach and colon was prepared and poured into a separate beaker. The UV spectra of these buffers were previously measured by an ultraviolet spectrometer. The drug- loaded hydrogel powder was then placed in buffer solutions using the tea-bag method and the drug release was measured by a UV spectrometer for 8 hours in 37 ${ }^{\circ} \mathrm{C}$.

\section{Results and discussion}

Mechanism of synthesis of silver nanocomposite hydrogels

In the first step, silver nanocomposite hydrogels were synthesized through a photochemical reaction. Silver cations were then reduced to silver nanoparticles in the presence of indirect sunlight. The silver ions, initially bonded to the hydroxyl groups of glucomannan units in saleb, were converted to silver nanoparticles during this photochemical reaction. In the second stage, APS, as a primer, was decomposed under the influence of heat and produced sulfate anion radicals. The sulfate anion radical attacks the anomeric or hydroxyl hydrogen groups present in the glaucoma polysaccharide units of the potassium, and the $\mathrm{C}-\mathrm{H}$ or $\mathrm{O}-\mathrm{H}$ bond of the polysaccharide chain is broken. The oxidation and reduction system, persulfate-saccharide, causes a radicalization polymerization reaction in which AA monomers are converted to Polly acrylic acid (PAA) and VP to Polly vinylpyrrolidone (PVP) and bond with the radicals of the glaucoma units of salep. The addition of the MBA crosslinker agent creates crosslinks in the synthesized copolymer structure and a silver nanocomposite superabsorbent is formed.

\section{Optimization of silver nanocomposite hydrogels}

To increase the water absorption rate of silver nanocomposite hydrogels, the factors affecting water absorption such as monomers were optimized. In this study, the water absorption rates in all optimization steps after five hours were reported and the weight of synthesized hydrogel powder in all cases was $0.02 \mathrm{~g}$.

\section{The effect of $\mathrm{AgNO}_{3}$ value}

The swelling rate of silver nanocomposite hydrogel increases with increasing the weight of $\mathrm{AgNO}_{3}$ to $0.01 \mathrm{~g}$ and reaches $697.1 \mathrm{~g} / \mathrm{g}$ and then decreases with increasing the weight of $\mathrm{AgNO}_{3}$.

Table 1. The effect of $\mathrm{AgNO}_{3}$ value on swelling

\begin{tabular}{|c|c|c|c|c|c|c|}
\hline $\begin{array}{c}\text { Swelling } \\
\text { rate } \\
\text { (gr/gr) }\end{array}$ & $\begin{array}{c}\text { Salep } \\
\text { (gr) }\end{array}$ & $\begin{array}{c}\text { VP } \\
\text { (gr) }\end{array}$ & $\begin{array}{c}\text { AA } \\
\text { (gr) }\end{array}$ & $\begin{array}{c}\text { APS } \\
\text { (gr) }\end{array}$ & $\begin{array}{c}\text { MBA } \\
\text { (gr) }\end{array}$ & $\begin{array}{c}\text { AgNO } \\
\text { (gr) }\end{array}$ \\
\hline 553.50 & 1 & 2 & 3 & 0.05 & 0.05 & 0 \\
\hline 566.11 & 1 & 2 & 3 & 0.05 & 0.05 & 0.001 \\
\hline 697.01 & 1 & 2 & 3 & 0.05 & 0.05 & 0.01 \\
\hline 350.13 & 1 & 2 & 3 & 0.05 & 0.05 & 0.03 \\
\hline 317.09 & 1 & 2 & 3 & 0.05 & 0.05 & 0.06 \\
\hline 258.13 & 1 & 2 & 3 & 0.05 & 0.05 & 0.09 \\
\hline
\end{tabular}

\section{The effect of MBA value}

As the amount of MBA increases, the swelling rate of the synthesized hydrogel decreases so that the maximum swelling rate $(766.87 \mathrm{~g} / \mathrm{g})$ corresponds to the minimum MBA rate $(0.03 \mathrm{~g})$. 


\section{APS value}

Increasing the amount of APS initially increases the swelling rate in the silver nanocomposite hydrogel so that the maximum adsorption rate $(766.87 \mathrm{~g} / \mathrm{g})$ occurs when $0.05 \mathrm{~g}$ of ammonium persulfate is used as a primer.

\section{The effect of $A A / V P$ ratio}

The addition of monomer initially increases the swelling rate of the synthesized hydrogel so that the maximum adsorption rate $(1853 / 90 \mathrm{~g} / \mathrm{g})$ corresponds to the minimum AA/VP ratio $(1.2 \mathrm{~g} / \mathrm{g})$, but with a gradual increase in the monomers, the swelling rate of the hydrogel decreases.

\section{The time effect}

As shown in Figure 1, the swelling rate of the hydrogel increased over time from 150 minutes to 300 minutes at a constant rate so that the highest swelling rate $(1853 / 90 \mathrm{~g} / \mathrm{g})$ in 300 minutes was reported. (according Eq.1)

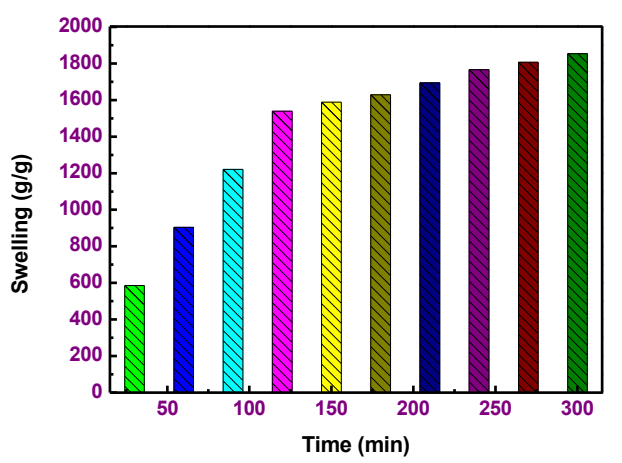

Fig.1. The effect of time on the swelling rate of silver nanocomposite hydrogels

\section{Temperature effect}

The swelling rate of the synthesized hydrogel increased with increasing temperature.

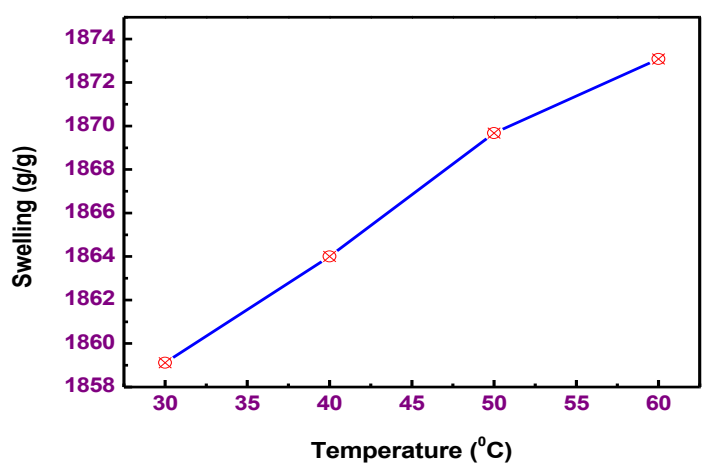

Fig.2. The effect of temperature on the swelling rate of silver nanocomposite hydrogels

\section{The effect of pressure}

The swelling capacity of the synthesized hydrogel decreased under pressure. To determine the mechanical strength of silver nanocomposite hydrogel, the optimal sample was subjected to a pressure of 0.3 psi $(45 \mathrm{~g})$ and the maximum swelling rate $(165.1054 \mathrm{~g} /$ g) was reported after 5 hours.

\section{The effect of absorption rate under pressure in $0.1 M$ $\mathrm{KCl}$ solution}

The absorption rate of silver nanocomposite hydrogel in the presence of $0.1 \mathrm{M} \mathrm{KCl}$ solution and under pressure was drastically reduced so that the maximum swelling rate after 5 hours was reported to be $236.7 \mathrm{~g} / \mathrm{g}$.

\section{The effect of water and ethanol}

By increasing the ethanol/water ratio, the swelling rate of the hydrogel decreased so that by increasing the percentage of ethanol from $20 \%$ to $100 \%$, the swelling rate decreased from $677 \mathrm{~g} / \mathrm{g}$ to $142 \mathrm{~g} / \mathrm{g}$.

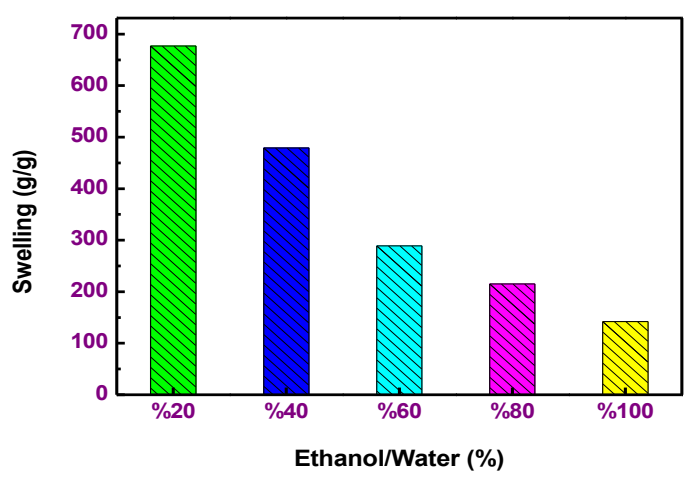

Fig.3. The effect of Ethanol/Water on the swelling rate of silver nanocomposite hydrogels

\section{The effect of $\mathrm{KCl}$ salt at different concentrations}

Increasing the salt concentration from $0.001 \mathrm{M}$ to $0.5 \mathrm{M}$ reduced the swelling rate of the hydrogel from $1552.71 \mathrm{~g} / \mathrm{g}$ to $751 \mathrm{~g} / \mathrm{g}$.

\section{The effect of monovalent, divalent, and trivalent salts}

In general, the presence of salts decreased the swelling capacity of the hydrogel, and this decrease was intensified by increasing the capacity of the salts.

\section{The pH effect}

The swelling rate increased with increasing $\mathrm{pH}$, reaching its maximum at $\mathrm{pH}=8(755.97 \mathrm{~g} / \mathrm{g})$ and then beginning to decrease again.

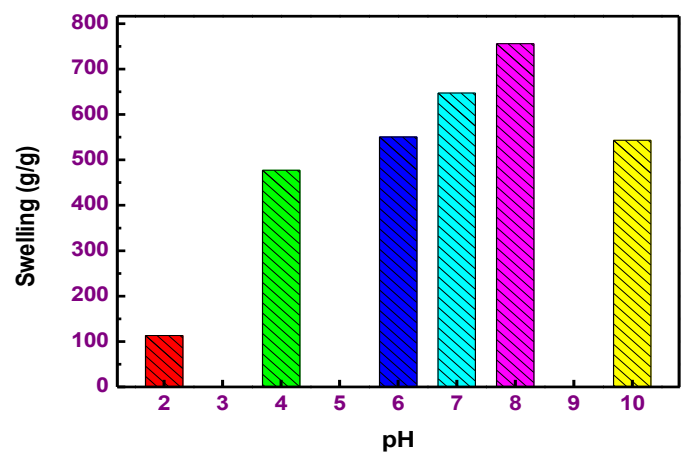

Fig.4. The effect $\mathrm{pH}$ on the swelling rate of silver nanocomposite hydrogels 


\section{Release of deferasirox}

To measure the drug release rate in these two environments, the extinction coefficient $(\varepsilon)$ of deferasirox was first measured.

\section{Measurement of the extinction coefficient of deferasirox}

To measure the extinction coefficient (molar absorption coefficient) of deferasirox, solutions with concentrations of $4 \times 5^{-10}, 3 \times 5^{-10}, 2.03 \times 5^{-10}, 1.69 \times 5^{-10}$, $1.45^{\times} 5^{-10}, 1.27 \times 5^{-10}, 1.13 \times 5^{-10}, 1.01 \times 5^{-10}$, and $9.25 \times 5^{-10}$ were prepared and their spectra were recorded by an ultraviolet spectrometer. Then, the calibration curve of deferasirox was drawn. As can be seen (Figure 5), the extinction coefficient $(\varepsilon)$ is equal to the slope of the curve of absorption changes in terms of concentration.

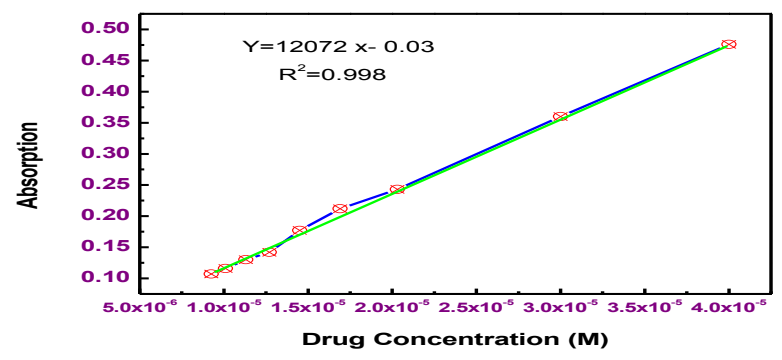

Fig.5. Deferasirox calibration

\section{Drug release mechanism}

The drug release rate at $\mathrm{pH}=8$ is higher than $\mathrm{pH}=2$, which can be justified by the swelling pattern of silver nanocomposite hydrogels at different $\mathrm{pHs}$. Furthermore, according to Figure 6, at both $\mathrm{pH}$ values, the drug release rate increases from 360 minutes and is fixed after 480 minutes, showing a favorable time for the drug to pass through the stomach without the interference of stomach acid.

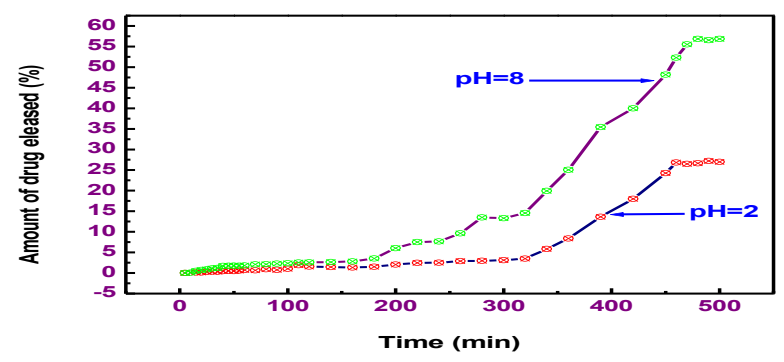

Fig.6. Deferasirox release over time at $\mathrm{pH}=2$ and $\mathrm{pH}=8$

The Beer-Lambert equation was used to measure the drug release rate:

$$
\mathrm{A}=\mathrm{bc \varepsilon}
$$

Where $\mathrm{A}$ is the absorption rate, $\varepsilon$ is the extinction coefficient $\left(\mathrm{Lcm}^{-1} \mathrm{~mol}^{-1}\right), \mathrm{b}$ is the length of the radiation path from inside the solution in $\mathrm{cm}$, and $\mathrm{c}$ is the concentration of the solution $\left(\mathrm{mol} \mathrm{L}^{-1}\right)$.

\section{TGA analysis}

As can be seen in Figure 7, the first thermal degradation begins at $55^{\circ} \mathrm{C}$ and continues up to $100{ }^{\circ} \mathrm{C}$. The rate of degradation is $3 \%$ and is related to water loss. Then, in the temperature range of $325-260{ }^{\circ} \mathrm{C}$, severe degradation $(44 \%)$ occurs and this degradation continues up to $590{ }^{\circ} \mathrm{C}$ with less intensity $(13 \%)$. This degradation occurs due to the $\mathrm{CO}_{2}$ loss. As shown in the DTG curve, as a derivative of the TGA curve, the maximum degradation rate can be seen in the temperature range of $250-330{ }^{\circ} \mathrm{C}$.

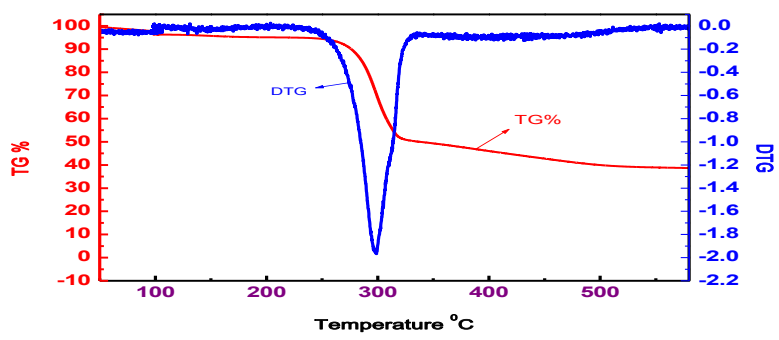

Fig.7. TGA and DTG curves

\section{FT-IR analysis}

In the salep spectrum, a broad peak is observed in the range of $3500-3000 \mathrm{~cm}^{-1}$, which is due to the tensile vibrations of $\mathrm{O}-\mathrm{H}$ in the glucomannan chain, and in the $\mathrm{C}-\mathrm{H}\left(\mathrm{sp}^{3}\right)$ tensile vibrations result in a mediumintensity peak (frequency at which $\mathrm{CH}$ is absorbed) that represents the type of carbon to which hydrogen is attached, increasing the S-property of adsorption toward frequencies above $3000 \mathrm{~cm}^{-1}$. The tensile vibrations of the $\mathrm{C}=\mathrm{O}$ group in the range of $1700-1730 \mathrm{~cm}^{-1}$ also belong to the acetate group in glucomannan, and the bending vibrations in the range of $1465 \mathrm{~cm}^{-1}$ belong to the $\mathrm{CH}_{2}$ group. In the range of $1079-1100 \mathrm{~cm}^{-1}$, a highintensity peak is observed which has been occurred due to the tensile vibrations of the single bond of the C-O group on the loop.

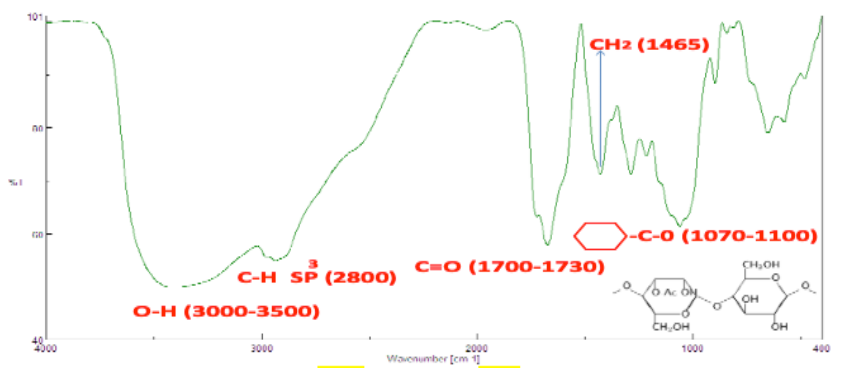

Fig.8. IR spectra of salep

Besides, in the acrylic acid spectrum, the $\mathrm{O}-\mathrm{H}$ tensile vibrations in the range of $2800-3300 \mathrm{~cm}^{-1}$ show a very wide peak (a strong hydrogen bond) which, as shown in Figure 9, is often interferes with $\mathrm{C}-\mathrm{H}$ absorption. In the range of $1700-1730 \mathrm{~cm}^{-1}$, the $\mathrm{C}=\mathrm{O}$ tensile vibrations $\mathrm{C}=\mathrm{O}$ generate a relatively wide peak. Due to the conjugation phenomenon, the absorption frequency decreases compared to the tensile vibrations of the carbonyl group in aldehydes and ketones. The $\mathrm{C}=\mathrm{C}$ tensile vibrations in the range of $1600-1660 \mathrm{~cm}^{-1}$ produce a peak of medium intensity and the absorption frequency of $\mathrm{C}-\mathrm{O}$ tensile vibrations appears in the range of $1210-1320 \mathrm{~cm}^{-1}$ and the $=\mathrm{C}-\mathrm{H}$ bending vibrations peak in the range of $690-900 \mathrm{~cm}^{-1}$. 


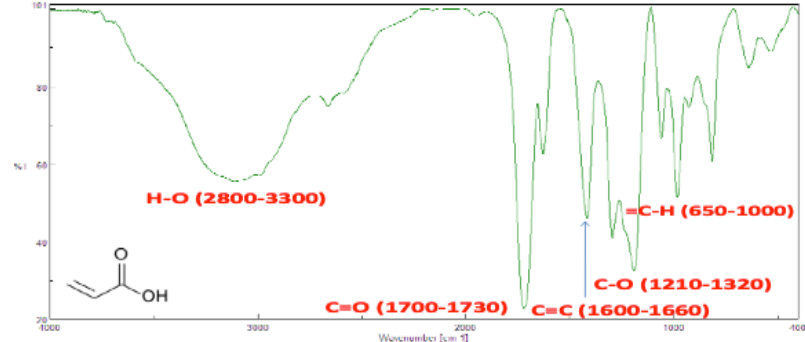

Fig.9. IR spectrum of acrylic acid

In the poly (acrylic acid) spectrum (Figure 10), the non-existence of the peaks related to the $\mathrm{C}=\mathrm{C}$ tensile vibration in the range of $1600-1660 \mathrm{~cm}^{-1}$ and the $\mathrm{C}-\mathrm{H}$ bending vibration in the range of $650-1000 \mathrm{~cm}^{-1}$ leads to the formation of the polymer chain. In this spectrum, the wide peak in the range of $3000-3400 \mathrm{~cm}^{-1}$ is related to the $\mathrm{H}-\mathrm{O}$ tensile vibration of the carboxyl group. The $\mathrm{C}=\mathrm{O}$ tensile vibration in the range of $1700-1730 \mathrm{~cm}^{-1}$ creates a high-intensity peak. The peak generated by the $\mathrm{CH}_{2}$ bending vibration appears in the range of 1465 $\mathrm{cm}^{-1}$. There is also a peak in the range of 1210-1320 $\mathrm{cm}^{-1}$, which is generated by the C-O tensile vibration.

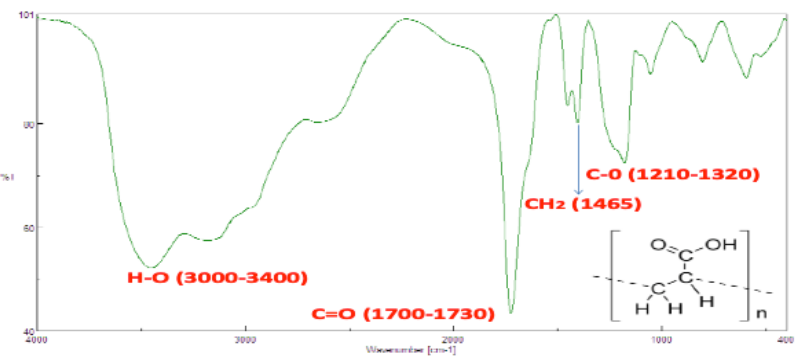

Fig.10. Poly (acrylic acid) IR spectrum

In the vinyl pyrrolidone spectrum (Figure 11), the $=\mathrm{C}-\mathrm{H}\left(\mathrm{sp}^{2}\right)$ absorption frequency of tensile vibration shows its peak in the range of $3000 \mathrm{~cm}^{-1}$ and the $\mathrm{C}=\mathrm{O}$ tensile vibration reaches its peak in the range of 1680 $\mathrm{cm}^{-1}$. The carbonyl group shows a decrease in the absorption frequency in this compound due to the resonance of the non-bonded electron pair of nitrogen with the carbonyl group, which leads to an increase in the simple bond property and a change in the adsorption frequency. The absorption peak of the $\mathrm{C}=\mathrm{C}$ tensile vibration is observed in the range of $1630 \mathrm{~cm}^{-1}$, and also the $=\mathrm{C}-\mathrm{H}$ bending vibration peaks in the range of $650-1000 \mathrm{~cm}^{-1}$.

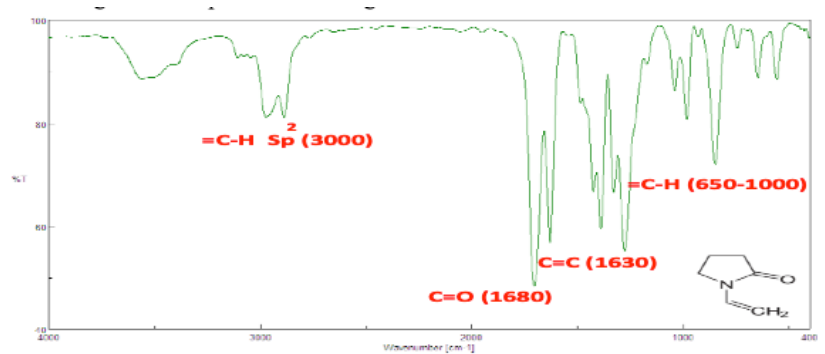

Fig.11. Vinyl pyrrolidone IR spectrum

In the poly (vinyl pyrrolidone) spectrum (Figure 12), a peak appears in the range of $2900 \mathrm{~cm}^{-1}$, which belongs to the $\mathrm{C}-\mathrm{H}$ tensile vibration. With the conversion of vinylpyrrolidone to poly (vinylpyrrolidone), the $=\mathrm{C}-\mathrm{H}\left(\mathrm{sp}^{2}\right)$ tensile vibration changes its peak in the range of $3000 \mathrm{~cm}^{-1}$ to the C$\mathrm{H}\left(\mathrm{sp}^{3}\right)$ tensile vibration peak in the range of $2900 \mathrm{~cm}^{-1}$. This change in the absorption frequency is evidence of the polymerization of vinylpyrrolidone, and the $\mathrm{C}=\mathrm{O}$ tensile vibration peaks in the range of $1680 \mathrm{~cm}^{-1}$. In general, the $\mathrm{C}-\mathrm{C}$ tensile vibration peak is not suitable for interpretation due to the presence of high peaks.

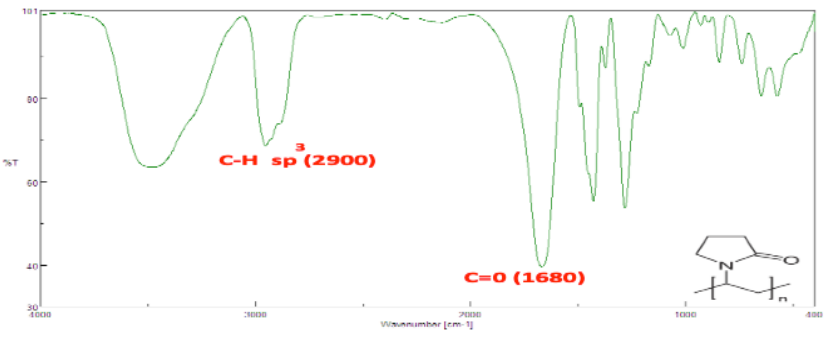

Fig.12. Poly (vinylpyrrolidone) IR spectrum

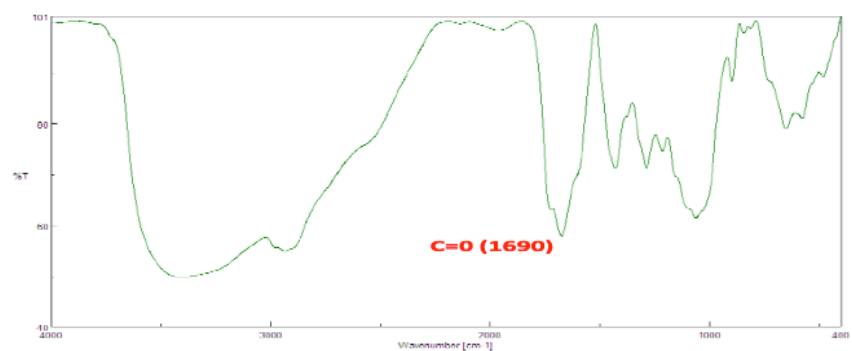

Fig.13. IR spectra of the nanocomposite hydrogels optimized without the presence of silver

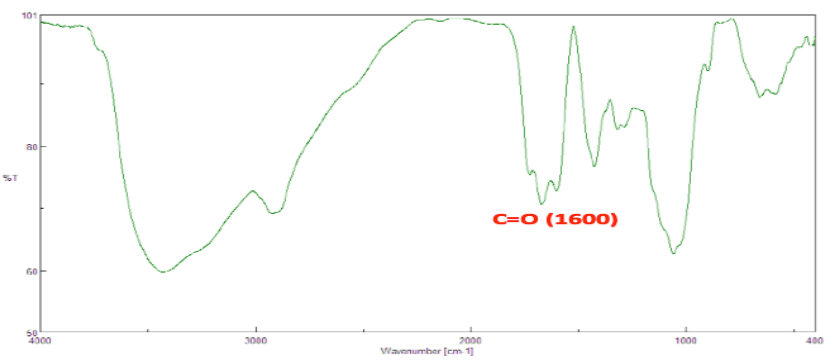

Fig.14. IR spectra of the optimized silver nanocomposite hydrogels

A comparison of the IR spectra of nanocomposite hydrogels in the presence and absence of silver (Figures 12-14) shows that in the presence of silver nanoparticles, the absorption frequency of $\mathrm{C}=\mathrm{O}$ tensile vibration changes from the range of 1960 to the range of $1600 \mathrm{~cm}^{-1}$. This change can be attributed to the uniform formation of the bonds between the silver nanoparticles and the $\mathrm{C}=\mathrm{O}$ electron groups in the hydrogel lattice. Besides, a comparison of the IR spectra of glucomannan polysaccharide and silver nanocomposite hydrogel proves the bonding of acrylic acid and vinyl pyrrolidone on the polysaccharide chain.

\section{SEM and TEM analysis}

Scanning electron microscopy (SEM) images were used to investigate the surfaces of silver nanocomposite hydrogels. As shown in Figure 15, the synthesized hydrogel has layered and porous surfaces, 
so that the swelling rate of the hydrogel can be attributed to its structure.

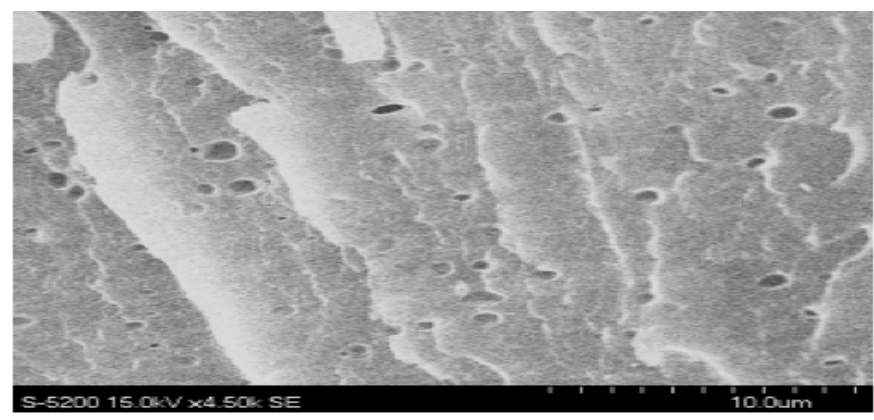

Fig.15. SEM image of silver nanocomposite hydrogel

Transmission electron microscopy (TEM) was used to determine the size of silver nanoparticles in the synthesized hydrogel network under optimal conditions. Figure 16 shows the uniform dispersion of silver nanoparticles in the hydrogel network:

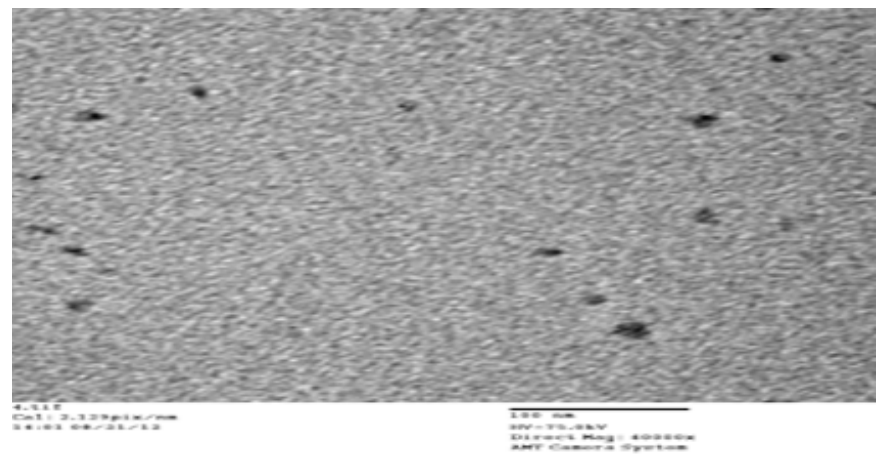

Fig.16. TEM image of silver nanocomposite hydrogel

Besides, by measuring the diameter of nanoparticles in the TEM image and converting them to nanometers using the image scale, the histogram of the silver nanocomposite hydrogel was drawn as shown in Figure 17. Accordingly, the average size of silver nanoparticles in the polymer network is $10.6 \mathrm{~nm}$.

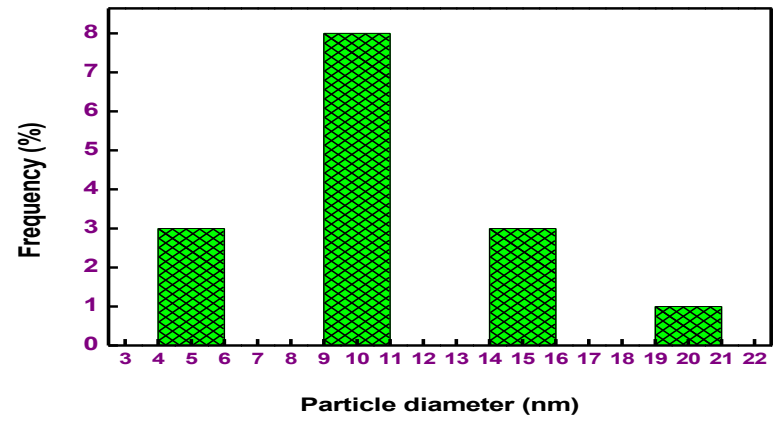

Fig.17. Histogram of silver nanocomposite hydrogel

\section{Conclusion}

This study showed that the release of deferasirox from the silver nanocomposite hydrogel network is related to the $\mathrm{pH}$ of the environment. In addition, this system can be used in the pharmaceutical industry due to its biodegradability and biocompatibility.

\section{References}

1. Yallapu MM, Othman SF, Curtis ET, Gupta BK, Jaggi M, Chauhan SC. Multi-Functional Magnetic Nanoparticles for Magnetic Resonance Imaging and Cancer Therapy. Biomaterials. 2011; 32: 1890-1905.

2. Goddard WA, Brenner D, Lyshevski SE, Iafrate GJ. Handbook of Nanoscience, Engineering, and Technology. Taylor \& Francis. 2nd Edition. 2007.

3. Pillai ZS, Kamat PV. What Factors Control the Size and Shape of Silver Nanoparticles in the Citrate Ion Reduction Method? J Phys Chem B. 2004; 108: 945-951.

4. Thostenson E, Li C, Chou T. Review Nanocomposites in Context. J Compos Sci Tech. 2005; 65: 491-516.

5. Hussain F, Hojjati M, Okamoto M, Gorga RE. Review Article: Polymer Matrix Nanocomposites, Processing, Manufacturing, and Application: An Overview. J Compos Mater. 2006; 40: 1511-1575.

6. Veiseh O, Gunn JW, Zhang M. Design and Fabrication of Magnetic Nanoparticles for Targeted Drug Delivery and Imaging. Adv Drug Deliv Rev. 2010; 62: 284-304.

7. Zohuriaan-Mehr MJ, Kabiri K. Superabsorbent Polymer Materials: A Review. Iran Polym J. 2008; 17: 451-477.

8. Chen X, Parker SG, Zou G, Su W, Zhang Q. BCyclodextrin-Induced Fluorescence Enhancement of a Thermal-Responsive Azobenzene Modified Polydiacetylene Vesicles for a Temperature Sensor. Mater Chem Phys. 2010; 124: 36-40.

9. Panacek A, Kvítek L, Prucek R. Silver Colloid Nanoparticles: Synthesis, Characterization, and their Activity. J Phys Chem B. 2006; 110: 16248-1653.

10. Signori AM, Santos Kde O, Eising R, Albuquerque BL, Giacomelli FC, Domingos JB. Formation of Catalytic Silver Nanoparticles Supported on Branched Polyethyleneimine Derivatives. Langmuir. 2010; 26: 17772-17779.

11. Sharma VK, Yngard RA, Lin Y. Silver Nanoparticles: Green Synthesis and their Antimicrobial Activities. Adv Colloid Interface Sci. 2009; 145: 83-96. 